\title{
Evidence for positive selection in the gene fruitless in Anastrepha fruit flies
}

\author{
Iderval S Sobrinho Jr, Reinaldo A de Brito
}

\begin{abstract}
Background: Many genes involved in the sex determining cascade have indicated signals of positive selection and rapid evolution across different species. Even though fruitless is an important gene involved mostly in several aspects of male courtship behavior, the few studies so far have explained its high rates of evolution by relaxed selective constraints. This would indicate that a large portion of this gene has evolved neutrally, contrary to what has been observed for other genes in the sex cascade.

Results: Here we test whether the fruitless gene has evolved neutrally or under positive selection in species of Anastrepha (Tephritidae: Diptera) using two different approaches, a long-term evolutionary analysis and a populational genetic data analysis. The first analysis was performed by using sequences of three species of Anastrepha and sequences from several species of Drosophila using the ratio of nonsynonymous to synonymous rates of evolution in PAML, which revealed that the fru region here studied has evolved by positive selection. Using Bayes Empirical Bayes we estimated that 16 sites located in the connecting region of the fruitless gene were evolving under positive selection. We also investigated for signs of this positive selection using populational data from 50 specimens from three species of Anastrepha from different localities in Brazil. The use of standard tests of selection and a new test that compares patterns of differential survival between synonymous and nonsynonymous in evolutionary time also provide evidence of positive selection across species and of a selective sweep for one of the species investigated.

Conclusions: Our data indicate that the high diversification of fru connecting region in Anastrepha flies is due at least in part to positive selection, not merely as a consequence of relaxed selective constraint. These conclusions are based not only on the comparison of distantly related taxa that show long-term divergence time, but also on recently diverged lineages and suggest that episodes of adaptive evolution in fru may be related to sexual selection and/or conflict related to its involvement in male courtship behavior.
\end{abstract}

\section{Background}

Several genes related to reproduction have shown higher rates of divergence than other genes in the genome $[1,2]$. This fast differentiation has been explained most often by positive selection mediated by sexual selection and/or sexual conflict $[1,3,4]$, though some have suggested relaxed selective constraints $[5,6]$. Because these genes show high levels of divergence and may possibly be directly involved with reproductive isolation, some authors have suggested that such genes may be the best candidates to distinguish species that diverged recently and should actually be considered speciation genes $[7,8]$.

\footnotetext{
* Correspondence: iderval_sobrinho_jr@yahoo.com

Universidade Federal de São Carlos, Departamento de Genética e Evolução, 13565-905. CP 676. São Carlos-SP. Brazil
}

Most evolutionary studies on genes related to sex differentiation have focused on a portion of those rapidly evolving genes involved in fertilization or male-female interaction and only a few on the genes responsible for sexual differentiation themselves. In Diptera, transformer (tra) and doublesex ( $d s x)$ are two of the main genes that control sexual differentiation that have been studied [5,9-11]. Another important gene in the sex-determination cascade is fruitless (fru), which controls the male courtship behavior by the establishment and development of a male-specific neuronal circuitry [12-14] along with $d s x$ [15]. Its genomic organization is conserved in several lineages of insects $[6,16]$ being composed of four main regions: sex-specific domain, dimerization domain (BTB), connecting region and DNA-binding domains

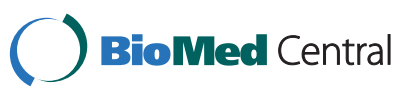

(c) 2010 Sobrinho and de Brito; licensee BioMed Central Ltd. This is an Open Access article distributed under the terms of the Creative Commons Attribution License (http://creativecommons.org/licenses/by/2.0), which permits unrestricted use, distribution, and reproduction in any medium, provided the original work is properly cited. 
(zinc-fingers) [12] (Figure 1A). The fru gene is alternatively spliced in a sex-dependent way from the P1 promoter, where the female transcript translation is interrupted by the binding of TRA/TRA-2 complex, whereas the male product is functional [17]. In sex-specific transcripts the exon (S) makes the first domain whereas, in non-sex-specific transcripts the first domain is composed by the BTB exons (Figure 1C). Depending on the species, the BTB domain is formed by one or two exons $(\mathrm{C} 1-\mathrm{C} 2)$. In the same way the connecting region is formed by two to four exons depending on the taxonomic group (C3-C5). Finally, the DNA-binding domain at the 3' end is composed of one of four different exons (A-D), selected by differential splicing $[6,16]$. In addition to the sex-specific transcripts, sex-nonspecific products are expressed by three different promoters (P2, P3 and P4) downstream to the exon S, which confers to fru a complex pattern of expression in different tissues and stages of the development $[18,19]$ (Figure $1 \mathrm{C})$.

Considering that fru is one of the key elicitors of male courtship behavior, variation in its nucleotide sequence could be subjected to sexual selection and thus be involved in lineage isolation and differentiation. Should this be the case, we would expect a pattern of rapid divergence in fru, especially in regions under positive selection. Indeed, the comparison among different insect lineages shows that the $\mathrm{N}$-terminal and the connecting region are the most divergent $[6,16]$, which has been hypothesized to be either a consequence of these regions not being essential for the proper function of FRU protein, or because they would contain information for species-specific male courtship behavior [6]. Although the hypothesis of species-specific signature was rejected by the rescue of $f r u$ function via ectopic expression [6], a formal study of selection patterns on this gene has not yet been performed.

In this work we study patterns of genetic variability in fru in tephritid (Diptera) species of the group fraterculus to contrast the hypotheses that the high divergence of the connecting region is due to a relaxed selective constraint or to positive selection over the region. These Anastrepha species from the group fraterculus are generally identified by subtle differences in morphological traits, particularly the aculeus [20], which limits the identification to females. The problem of identifying species in this group is further enhanced by the inherent plasticity of the aculeus [21] and possible existence of many cryptic species in the group [22]. This problem has not been placated by the use of some molecular

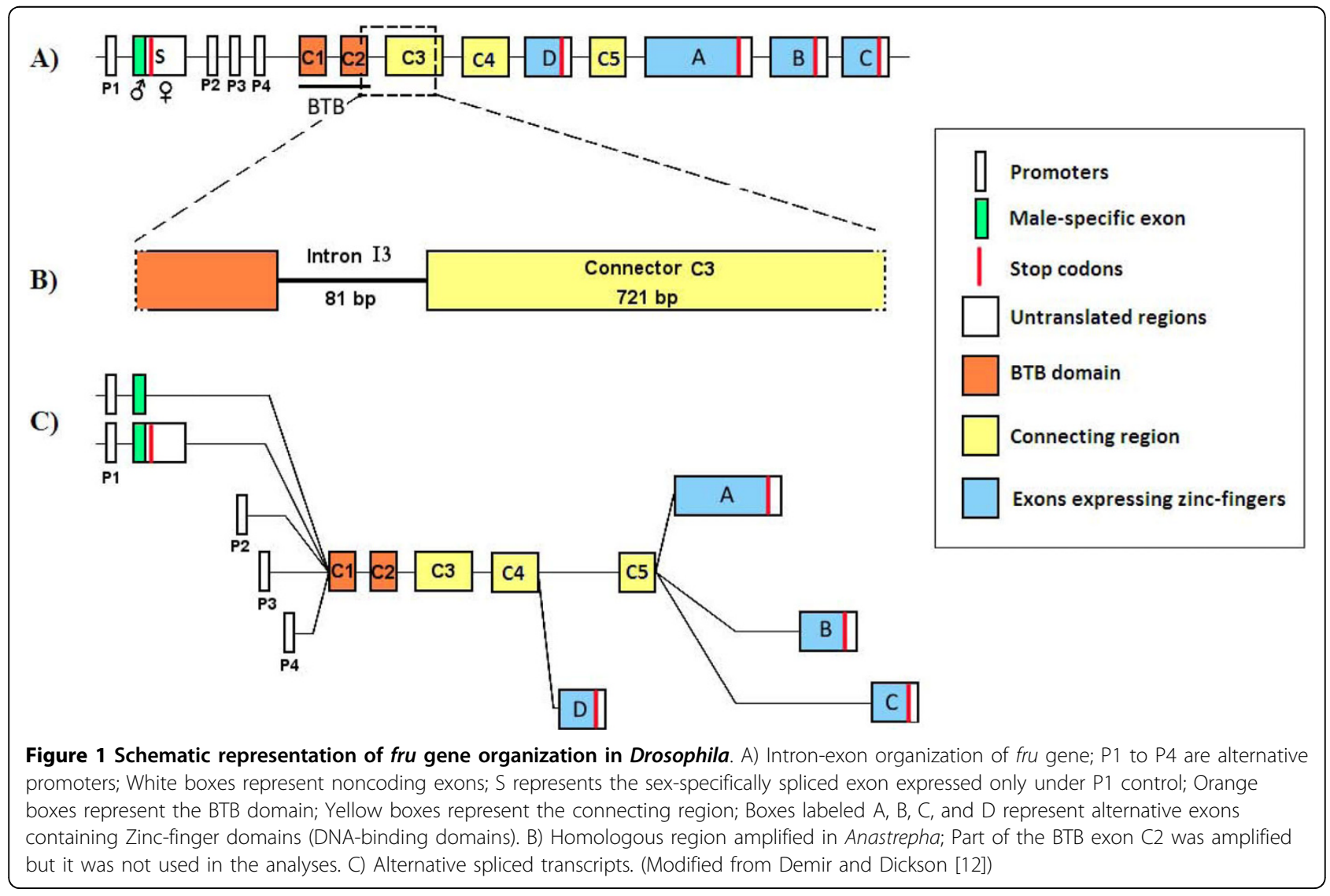


markers, such as mtCOI [23], doublesex [24] and transformer [25], which have, in general, shown low phylogenetic resolution. Therefore, even though we would like to test whether the gene fru would provide good genetic markers to discriminate species from the fraterculus group, notably A. fraterculus, A. sororcula and A. obli$q u a$, we are mostly interested in determining the effects of selection in this region, which is non-trivial since we are contrasting species and populations that diverged recently, where the use of standard $\mathrm{dN} / \mathrm{dS}$ methods [26-28] has been shown to be problematic [29]. Even though there is a plethora of neutrality tests already developed to detect departures from selection at the population level [30-32], the majority perform frequency analyses per nucleotide $[30,31,33]$, and few have used haplotype information $[34,35]$ or the phylogenetic relationships $[36,37]$ as a framework to investigate patterns of departure from neutrality. Here, we propose a test that uses such information to detect patterns of selection using population polymorphism data rather than fixed differences among lineages.

\section{Results}

Long-term evolutionary analyses and positive selection in fru

For the long-term evolutionary study of the fru connecting region, we amplified a region of 802 bp containing an $81 \mathrm{bp}$ intron (I3 intron) and $721 \mathrm{bp}$ of the first exon from the connecting region ( $\mathrm{C} 3$ exon) from three closely related Anastrepha species (A. fraterculus, A. sororcula and $A$. obliqua) (Figure 1B). The selective pressures over the fru $\mathrm{C} 3$ exon were investigated by the ratio of nonsynonymous to synonymous rates ratio. Table 1 shows the parameters inferred for the null models M1a and MA as well as for the alternative MA model. The relaxed branch-site test rejected the null model of selective constraint $(0<\omega \leq 1)$ indicating that the foreground branch (Figure 2) diverged in this region by relaxed selective constraint or by positive selection (Table 2). We contrasted the restricted MA versus MA models in the strict branch-site test to discriminate between the two hypotheses, and again the null model of selective constraint was rejected (Table 2) in favor of the hypothesis that part of the $\mathrm{C} 3$ exon differentiated by positive selection.

Using Bayes Empirical Bayes we estimated that 16 sites were evolving under positive selection with posterior probability greater than 0.95 (Table 2; Figure 3). Figure 3 shows that positively selected sites are concentrated in the $5^{\prime}$ half of the $\mathrm{C} 3$ exon, and that selectively constrained sites predominates in the terminal portion of the exon. The investigation of selection on amino acid properties in TreeSAAP analyses indicate that all 31 physicochemical properties examined showed significant departure from neutrality in the goodness-of-fit test, under a 0.05 cutoff limit (Table 3). Nevertheless, only three properties had significantly positive $\mathrm{z}$-scores under the radical changes categories (6 to 8): $\alpha$-helical tendencies $(P \alpha)$; Hydropathy $(H)$ and Molecular weight $(M w)$. The sliding window analysis in TreeSAAP also indicates positive-destabilizing selection in the 5 ' end of C3 exon (Figure 4). These macroevolutionary contrasts indicate presence of positive selection at the 5 ' end of $\mathrm{C} 3$ exon, whereas there is purifying selection at the 3 ' end of this exon.

\section{Analysis of Positive Selection at the Population Level}

Table 4 summarizes estimates of nucleotide variability for the region sequenced (I3 intron and C3 exon). Considering only the $\mathrm{C} 3$ exon of the 50 individuals sequenced from the three species, 167 polymorphic sites were found, nine with more than one nucleotide variant, violating the infinite allele model. The I 3 intron had 28 polymorphic sites, six of them with more than one nucleotide variant (Table 4). The comparison among sequences also revealed 38 different intron haplotypes and $94 \mathrm{C} 3$ exon haplotypes, with the majority composed by unique haplotypes, revealed by the high haplotype diversity levels both for intron and exon. Diversity indexes for the coding regions show that synonymous nucleotide diversities $\left(\pi_{\mathrm{s}}\right)$ are greater than nonsynonymous nucleotide diversities $\left(\pi_{\mathrm{a}}\right)$ (z-values for all $\pi_{\mathrm{a}} \times \pi_{\mathrm{s}}$ comparisons were lower than $-30, p<0.001$ ) (Table 4). Because recombination may affect nucleotide diversity and may destroy historical information in a region, we used the software $R D P$, which failed to detect any significant signal of recombination.

Table 1 Parameters estimates and log likelihood values for branch-site M1a, MA and restricted MA model

\begin{tabular}{lll}
\hline Model & Parameters & Lnl \\
\hline M1a & $\omega_{0}=0.065 p_{0}=0.870$ & -3647.925 \\
Relaxed branch-site test null model & $\omega_{1}=1.000 p_{1}=0.130$ & -3629.574 \\
Restricted MA $\left(\omega_{2}=1\right.$, fixed) & $\omega_{0}=0.050 \omega_{2}=1.000$ & -3627.665 \\
Strict branch-site test null model & $p_{0}=0.653 p_{1}=0.096(p 2+p 3)=0.252$ & \\
MA & $\omega_{0}=0.053 \omega_{2}=82.666$ & \\
Alternative model & $p_{0}=0.679 p_{1}=0.093(p 2+p 3)=0,228$ & \\
\hline
\end{tabular}

$\mathrm{LnI}=\log$ likelihood; $\omega_{0}=\mathrm{dN} / \mathrm{dS}$ values for sites with $0<\omega<1 ; \omega_{1}=\mathrm{dN} / \mathrm{dS}$ values fixed to $1 ; \omega_{2}=\mathrm{dN} / \mathrm{dS}$ values for sites with $\omega>1$, which corresponds only to sites in the foreground branch. 


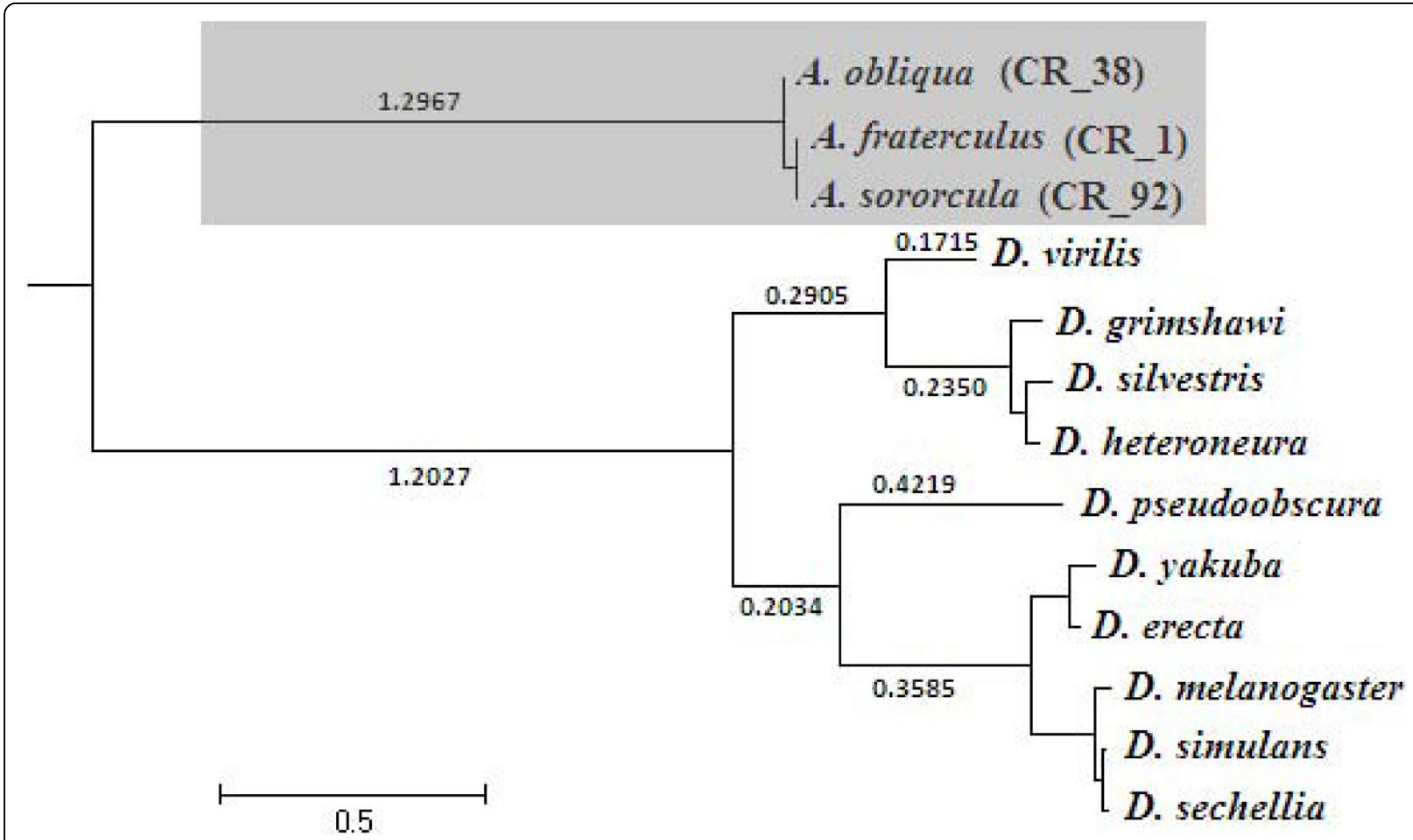

Figure $2 \mathrm{ML}$ phylogenetic tree of fru C3 exon used for detection of selection. The foreground branch is highlighted in gray. The genetic distances are in nucleotide substitutions per codon.

We performed several neutrality tests on the populational data separated by species. The analyses on the exon of A. obliqua revealed that all tests were significantly negative, whereas only Fay and Wu's $H$ and Tajima's $D$ were significantly negative for $A$. fraterculus and $A$. sororcula. On the other hand, when these tests were performed on the intron data, we only got significant departures from neutrality in A. obliqua for the Tajima's $D$ test and Fay and Wu's $H$ and in $A$. fraterculus for the Fay and Wu's $H$ test (Table 5). We used statistical parsimony to establish haplotype networks for the C3 exon (Figure 5) and for the I3 intron (Figure 6). Because these haplotype networks fail to indicate long branches separating the different species here studied, we also performed the neutrality tests combining all sequences in a single set. When we do so, all neutrality tests performed either on the intron or on the exon data are significantly negative (Table 5).
The topology of the haplotype network was then used to compare the probability of survival through time of synonymous and nonsynonymous mutations by estimating the number of haplotypes defined by each type of substitution. We observed 86 tip nonsynonymous mutations to 93 tip synonymous mutations, and 23 interior nonsynonymous to 44 synonymous mutations. The data from fru gene in Anastrepha (Table 6) indicate that, in spite of their smaller number, nonsynonymous mutations define, on average, haplotypes with higher frequencies than those defined by synonymous mutations. This is indicated by a significant two-tailed Mann-Whitney ranking test $(U=106$; $p<$ 0.02 ), in which we observe that nonsynonymous mutations have a mean rank of 29.7 and mean number of derived haplotypes of 27.8 , whereas synonymous substitutions have a mean rank of 22.7 and mean number of derived haplotypes of 6.2 .

Table 2 Comparison of null and alternative models by LRT and positively selected sites estimated by Bayes Empirical Bayes

\begin{tabular}{lccccl}
\hline Test & Contrast & LRT & D.F. & $\chi^{2}$ - Probability & Positively selected sites \\
\hline Relaxed branch-site & M1a $\times$ MA & 40.520 & 2 & $p<10^{-8}$ & $16,25,31,49,61,64,65,83,105,111,131$, \\
Strict branch-site & Restricted MA $\times$ MA & 3.817 & 1 & $p<0.05$ & $164,167,188,194,195$ \\
\hline
\end{tabular}

LRT - likelihood ratio test; D.F - Degrees of freedom. 


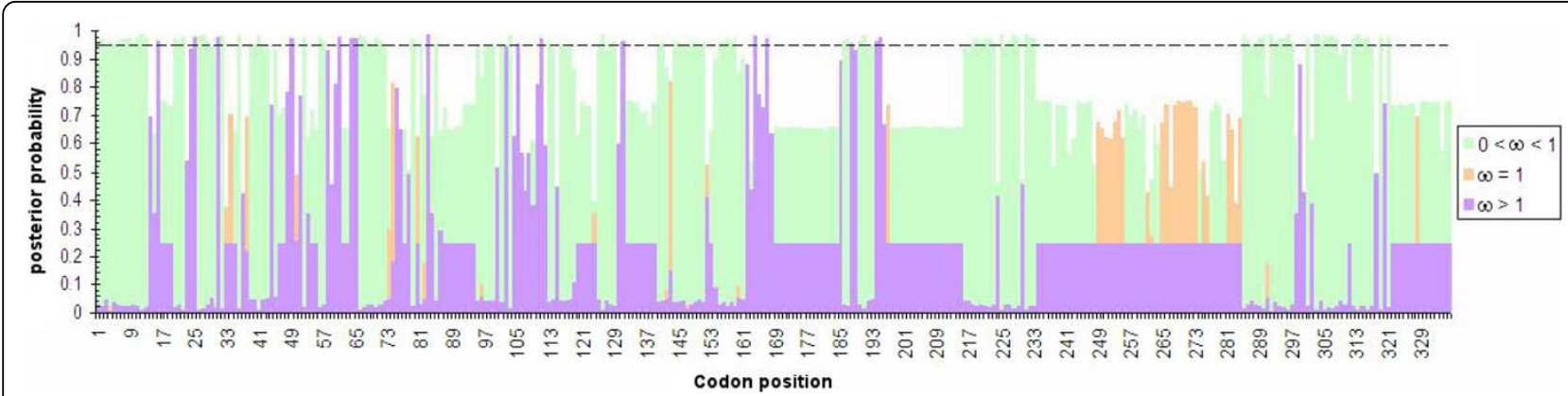

Figure 3 Posterior probabilities for sites in fru C3 exon to evolve under purifying selection $(0<\omega<1)$; positive selection $(\omega>1)$ and neutrality $(\omega=1)$. The dashed line stands for 0.95 posterior probability limit.

\section{Discussion}

\section{Positive selection in fru C3 exon}

Comparisons of fru sequences from insects of very distinct evolutionary lineages show that regardless of the high evolutionary conservation of the BTB and DNAbinding domains, the connecting region show high divergence across the different species studied $[6,16]$. These results are compatible with relaxed selective

Table 3 Amino acid physicochemical properties under positive destabilizing selection in fru C3 exon

\begin{tabular}{|c|c|c|c|}
\hline Physicochemical property & $\begin{array}{c}\text { Goodness-of-fit } \\
\text { (neutral expectation) }\end{array}$ & $\begin{array}{l}\text { radical change category } \\
(6,7 \text { e } 8)\end{array}$ & z-score \\
\hline Alpha-helical tendencies $\left(P_{\alpha}\right)$ & $36.498^{* * *}$ & 8 & $1.975^{*}$ \\
\hline Average number of surrounding residues $\left(N_{s}\right)$ & $76.820^{* * *}$ & - & - \\
\hline Beta-structure tendencies $\left(P_{\beta}\right)$ & $67.631^{* * *}$ & - & - \\
\hline Bulkiness $\left(B_{l}\right)$ & $40.169^{* * *}$ & - & - \\
\hline Buriedness $\left(B_{r}\right)$ & $47.688^{* * *}$ & - & - \\
\hline Chromatographic index $\left(R_{f}\right)$ & $65.981^{* * *}$ & - & - \\
\hline Coil tendencies $\left(P_{c}\right)$ & $82.908^{* * *}$ & - & - \\
\hline Composition $(C)$ & $52.020^{* * *}$ & - & - \\
\hline Compressibility $\left(K^{0}\right)$ & $36.874^{* * *}$ & - & - \\
\hline Equilibrium constant (ionization of $\mathrm{COOH}$ ) ( $p K$ ) & $33.814^{* * *}$ & - & - \\
\hline Helical contact area $\left(C_{a}\right)$ & $41.651^{* * *}$ & - & - \\
\hline Hydropathy $(H)$ & $92.128^{* * *}$ & 6 & $4.972^{* * *}$ \\
\hline Isoelectric point $\left(p H_{i}\right)$ & $56.298^{* * *}$ & - & - \\
\hline Long-range non-bonded energy $\left(E_{l}\right)$ & $38.021^{* * *}$ & - & - \\
\hline Mean r.m.s. fluctuation displacement $(F)$ & $57.826^{* * *}$ & - & - \\
\hline Molecular volume $\left(M_{v}\right)$ & $48.275^{* * *}$ & - & - \\
\hline Molecular weight $\left(M_{w}\right)$ & $53.230^{* * *}$ & 6 & $3.928^{* * *}$ \\
\hline Normalized consensus hydrophobicity $\left(H_{n c}\right)$ & $29.042^{* * *}$ & - & - \\
\hline Partial specific volume $\left(V^{0}\right)$ & $22.173^{* *}$ & - & - \\
\hline Polar requirement $\left(P_{r}\right)$ & $77.854^{* * *}$ & - & - \\
\hline Polarity $(P)$ & $117.046^{* * *}$ & - & - \\
\hline Power to be at the C-terminal of alpha-helix $\left(\alpha_{c}\right)$ & $57.177^{* * *}$ & - & - \\
\hline Power to be at the middle of alpha-helix $\left(\alpha_{m}\right)$ & $40.309^{* * *}$ & - & - \\
\hline Power to be at the N-terminal of alpha-helix $\left(\alpha_{n}\right)$ & $35.782^{* * *}$ & - & - \\
\hline Refractive index $(\mu)$ & $17.263^{*}$ & - & - \\
\hline Short and medium range non-bonded energy $\left(E_{s m}\right)$ & $73.460^{* * *}$ & - & - \\
\hline Solvent accessible reduction ratio $\left(R_{a}\right)$ & $16.175^{*}$ & - & - \\
\hline Surrounding hydrophobicity $\left(H_{p}\right)$ & $90.284^{* * *}$ & - & - \\
\hline Thermodynamic transfer hydrophobicity $\left(H_{t}\right)$ & $90.401^{* * *}$ & - & - \\
\hline Total non-bonded energy $\left(E_{t}\right)$ & $32.042^{* * *}$ & - & - \\
\hline Turn tendencies $\left(P_{t}\right)$ & $45.706^{* * *}$ & - & - \\
\hline
\end{tabular}

${ }^{*} p<0.05 ;{ }^{* *} p<0.01 ; * * * 0.001$ 

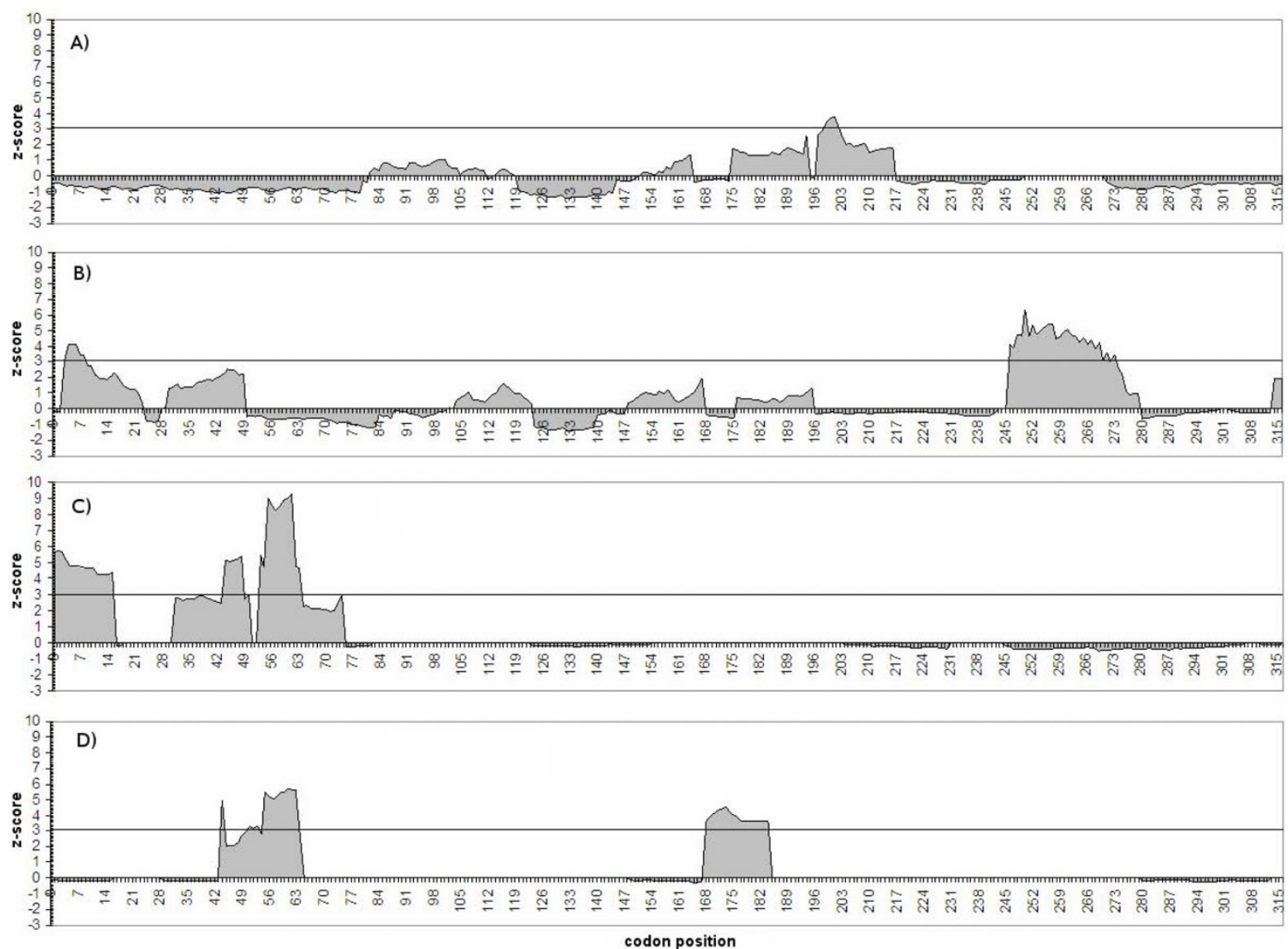

Figure 4 Sliding window plots of the z-scores of radically changed properties showing regions under positive-destabilizing selection in fru C3 exon. Dashed horizontal line indicates the Bonferroni corrected significant limit $(z$-score $=3.09, p<0.001)$. A) $\alpha$-helical tendencies category 6 of radical change; B) $\alpha$-helical tendencies - category 8 of radical change; C) Hydropathy - category 6 of radical change; D) Molecular weight category 6 of radical change.

Table 4 Genetic diversity estimates in the fruitless C3 exon and intron

\begin{tabular}{|c|c|c|c|c|c|c|c|c|c|c|c|c|c|}
\hline & Species & $\mathbf{N}$ & h & $\begin{array}{l}H d \\
\text { (SD) }\end{array}$ & $S$ & $S_{y}$ & $\mathrm{~N}_{\mathrm{Sy}}$ & sg & $m_{3}$ & $\begin{array}{c}\pi \\
\text { (SD) }\end{array}$ & $\begin{array}{c}\pi_{\mathrm{s}} \\
\text { (SD) }\end{array}$ & $\begin{array}{c}\pi_{\mathrm{a}} \\
\text { (SD) }\end{array}$ & $\begin{array}{c}\theta \\
\text { (SD) }\end{array}$ \\
\hline & A. fraterculus & 37 & 36 & $\begin{array}{c}0.998 \\
(0.007)\end{array}$ & 82 & 42 & 34 & 78 & 4 & $\begin{array}{c}0.011 \\
(0.0005)\end{array}$ & $\begin{array}{c}0.027 \\
(0.0021)\end{array}$ & $\begin{array}{c}0.006 \\
(0.0010)\end{array}$ & $\begin{array}{c}0.028 \\
(0.009)\end{array}$ \\
\hline \multirow[t]{4}{*}{ Exon } & A. obliqua & 41 & 40 & $\begin{array}{c}0.999 \\
(0.006)\end{array}$ & 80 & 41 & 39 & 77 & 3 & $\begin{array}{c}0.013 \\
(0.0005)\end{array}$ & $\begin{array}{c}0.026 \\
(0.0020)\end{array}$ & $\begin{array}{c}0.008 \\
(0.0007)\end{array}$ & $\begin{array}{c}0.027 \\
(0.008)\end{array}$ \\
\hline & A. sororcula & 19 & 19 & $\begin{array}{c}1.000 \\
(0.017)\end{array}$ & 62 & 39 & 26 & 60 & 2 & $\begin{array}{c}0.014 \\
(0.0005)\end{array}$ & $\begin{array}{c}0.034 \\
(0.0031)\end{array}$ & $\begin{array}{c}0.007 \\
(0.0011)\end{array}$ & $\begin{array}{c}0.025 \\
(0.009)\end{array}$ \\
\hline & Anastrepha sp. & 97 & 94 & $\begin{array}{c}0.999 \\
(0.002) \\
\end{array}$ & 167 & 83 & 78 & 157 & 9 & $\begin{array}{c}0.013 \\
(0.0005) \\
\end{array}$ & $\begin{array}{c}0.030 \\
(0.0015) \\
\end{array}$ & $\begin{array}{c}0.007 \\
(0.0004) \\
\end{array}$ & $\begin{array}{c}0.047 \\
(0.009) \\
\end{array}$ \\
\hline & A. fraterculus & 37 & 22 & $\begin{array}{c}0.922 \\
(0.030)\end{array}$ & 17 & - & - & 17 & 0 & $\begin{array}{c}0.027 \\
(0.0022)\end{array}$ & - & - & $\begin{array}{c}0.057 \\
(0.021)\end{array}$ \\
\hline \multirow[t]{3}{*}{ Intron } & A. obliqua & 41 & 11 & $\begin{array}{c}0.429 \\
(0.097)\end{array}$ & 8 & - & - & 8 & 0 & $\begin{array}{c}0.009 \\
(0.0024)\end{array}$ & - & - & $\begin{array}{c}0.026 \\
(0.012)\end{array}$ \\
\hline & A. sororcula & 19 & 13 & $\begin{array}{c}0.936 \\
(0.037)\end{array}$ & 16 & - & - & 15 & 1 & $\begin{array}{c}0.039 \\
(0.0058)\end{array}$ & - & - & $\begin{array}{c}0.064 \\
(0.026)\end{array}$ \\
\hline & Anastrepha sp. & 97 & 38 & $\begin{array}{c}0.834 \\
(0.032)\end{array}$ & 28 & - & - & 22 & 6 & $\begin{array}{c}0.026 \\
(0.0022)\end{array}$ & - & - & $\begin{array}{c}0.077 \\
(0.023)\end{array}$ \\
\hline
\end{tabular}

$\mathrm{N}=$ number of sequences; $\mathrm{h}=$ number of haplotypes; $H d=$ haplotype diversity; $\mathrm{S}=$ Number of polymorphic sites; $\mathrm{S}_{\mathrm{y}}=$ number of synonymous changes; $\mathrm{N}_{\mathrm{Sy}}=$ number of nonsynonymous changes; $\mathrm{sg}=$ singletons; $\mathrm{m}_{3}=$ sites with more than three variants; $\pi=$ nucleotide diversity; $\pi_{\mathrm{s}}=$ synonymous nucleotide diversity; $\pi_{\mathrm{a}}$ $=$ nonsynonymous nucleotide diversity; $\theta=$ Waterson's theta. SD = standard deviation. 
Table 5 Neutrality tests of C3 exon and intron

\begin{tabular}{|c|c|c|c|c|c|}
\hline & Species & $\begin{array}{l}\text { Fu and } \\
\text { Li's } D\end{array}$ & $\begin{array}{l}\text { Fu and } \\
\text { Li's } F\end{array}$ & $\begin{array}{l}\text { Fay and } \\
\text { Wu's } H\end{array}$ & $\begin{array}{c}\text { Tajima's } \\
D\end{array}$ \\
\hline & A. fraterculus & $-1.584^{a}$ & -2.197 & $-46.276^{* *}$ & $-2.244^{* *}$ \\
\hline \multirow[t]{4}{*}{ Exon } & A. obliqua & $-2.355^{*}$ & $-2.590^{*}$ & $-30.660^{* *}$ & $-1.924^{*}$ \\
\hline & A. sororcula & $-1.596^{a}$ & $-2.038^{\mathrm{a}}$ & $-24.883^{* *}$ & $-1.882^{*}$ \\
\hline & Anastrepha sp. & $-4.578^{*}$ & $-4.334^{*}$ & $-81.514^{* *}$ & $-2.435^{* *}$ \\
\hline & A. fraterculus & $-1.951^{\mathrm{a}}$ & $-2.157^{\mathrm{a}}$ & $-4.532^{*}$ & $-1.739^{a}$ \\
\hline \multirow[t]{3}{*}{ Intron } & A. obliqua & -1.181 & -1.389 & $-2.813^{*}$ & $-1.839^{*}$ \\
\hline & A. sororcula & -1.205 & -1.497 & -2.164 & -1.476 \\
\hline & Anastrepha sp. & $-3.528^{*}$ & $-3.412^{*}$ & $-8.766^{*}$ & $-1.989^{*}$ \\
\hline
\end{tabular}

${ }^{*} p<0.05$; ${ }^{*} p<0.01 ; a-$ not significant $(0.10>p>0.05)$

constraint on the latter portion of the gene or with divergence by positive selection. Here we contrast these two hypotheses using both, population and species level data from three species of Anastrepha to show that in all levels our data are better explained by positive selection acting on specific portions of the gene, rather than relaxed constraint in the connecting region (C3 exon).

The combination of the relaxed branch-site test (M1a vs. MA models) (Table 2) and the strict branch-site test (restricted MA $v s$. MA) demonstrates that part of the differentiation in the connecting region $\mathrm{C} 3$ exon from fru between the background (Drosophilidae) and foreground (Tephritidae) lineages is due to positive selection (Table 2). A BEB analysis detected at least 16 sites under positive selection, 14 of which were inserted in regions where positive-destabilizing selection was inferred by the MM01 analysis (Table 3, Figure 3 and Figure 4)

Because the BTB domain and the DNA-binding domains are generally conserved while the connecting region is highly divergent, it was suggested that the connecting region would either play no important role in FRU function or it would contain species-specific information. According to the first hypothesis, the higher divergence of the connecting region would be due to relaxed selective constraint or neutral evolution, whereas according to the second hypothesis its variation would be explained by adaptive selection. Gailey et al. [6] rejected this latter hypothesis because the transgenic expression of Anopheles fru in D. melanogaster rescued the Muscle of Lawrence (MOL) development, a structure that is specified only by male Fru ${ }^{\mathrm{M}}$ protein, which would imply that relaxed selective constraint or neutral evolution should be invoked to explain its variation. However, our studies on selective pattern in fru C3 exon from connecting region show signals of adaptive evolution in this region.

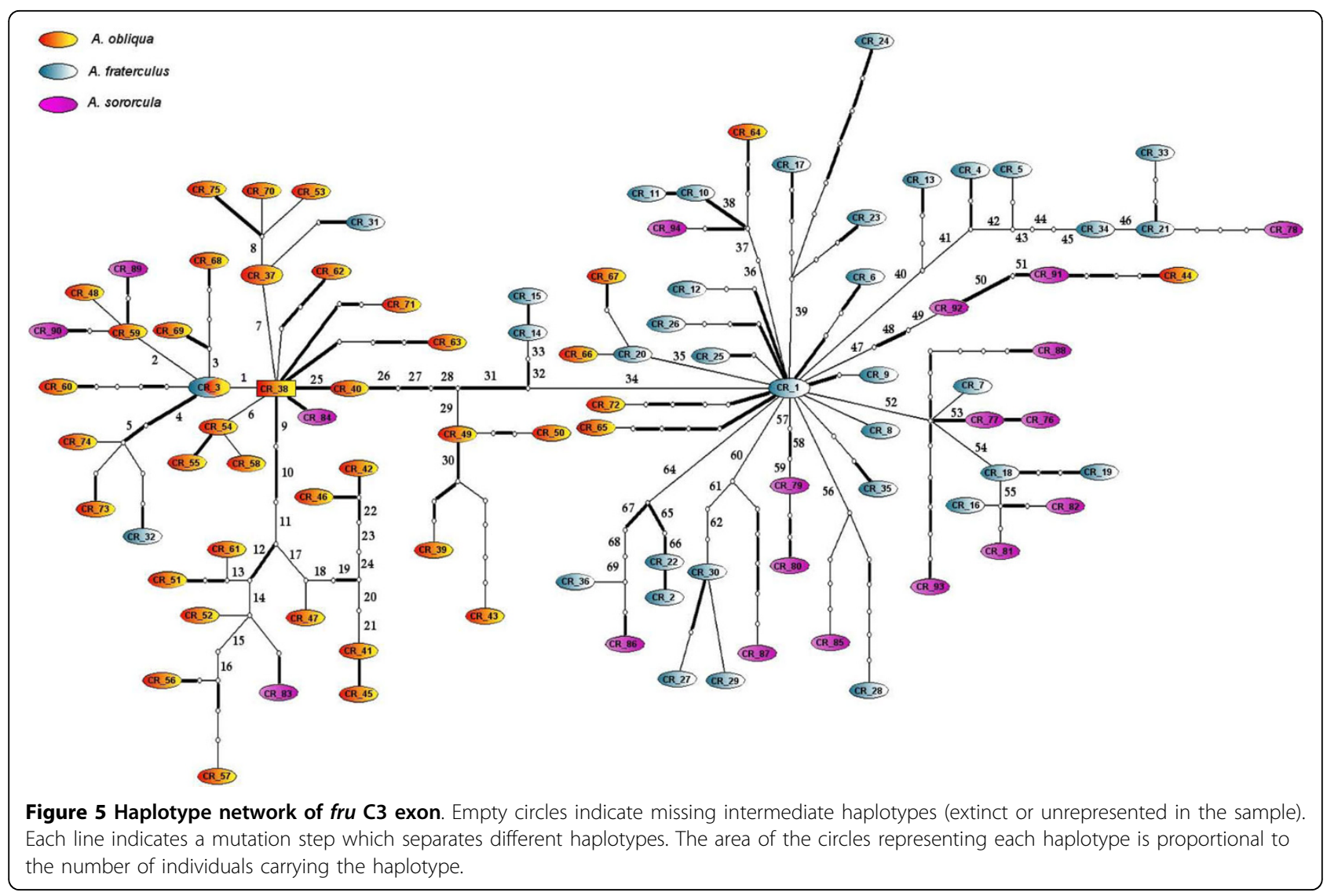




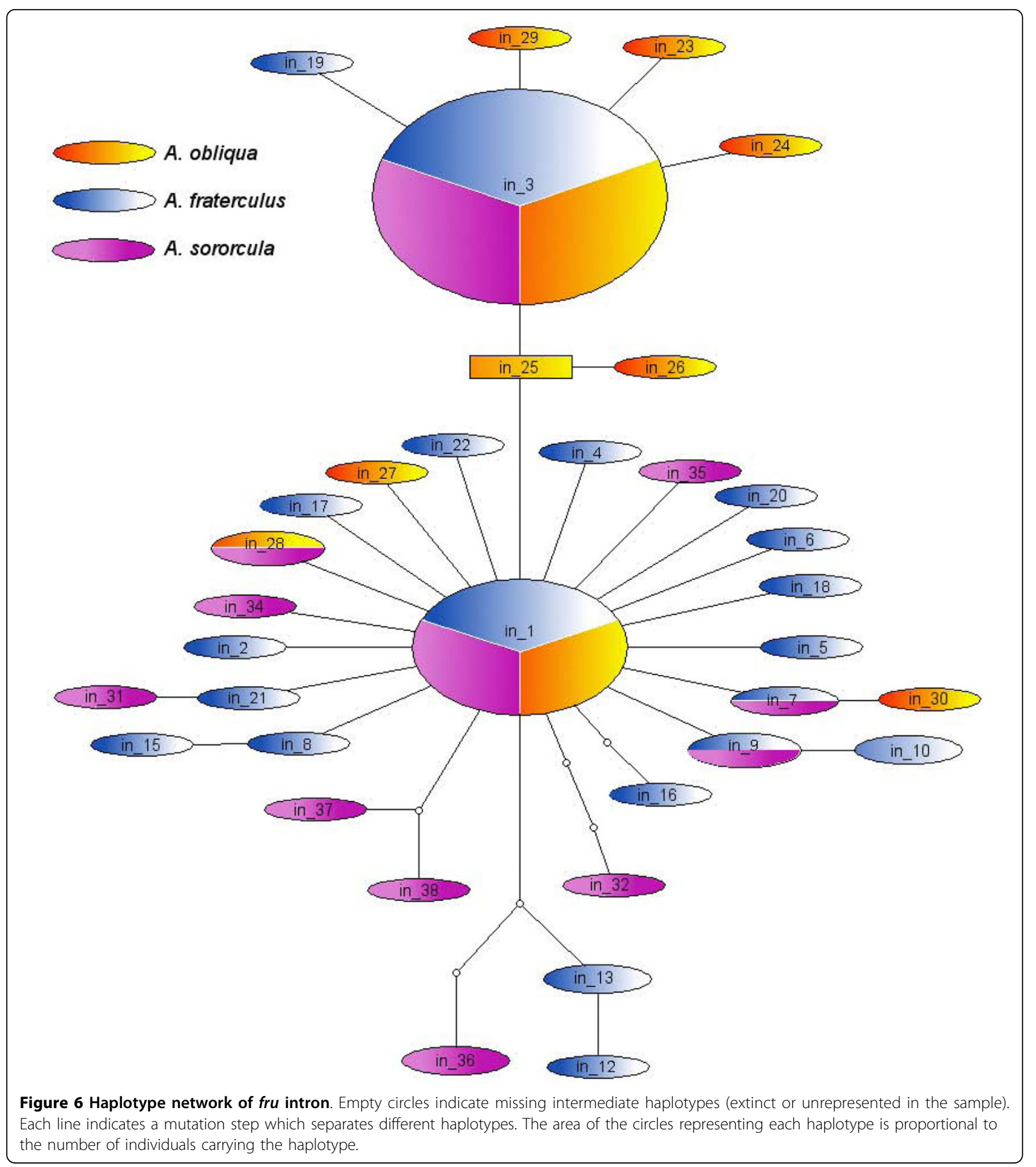

The gene fru is the most complex in terms of genomic organization, when compared to the other main genes from sex-determination cascade (doublesex and transfor$m e r)$. Due to alternative splicing, fru may be expressed in at least four different male isoforms and four nonsex-specific isoforms [12] (Figure 1C). The combination of these isoforms is required for the correct development of some neuronal circuitry and connections necessary to control courtship and copulation behavior [38] All these isoforms share four exons that are commonly expressed that include the BTB region and the connecting region. We sequenced a large portion of the latter 
Table 6 Frequency-based ranking of synonymous and nonsynonymous mutations

\begin{tabular}{|c|c|c|c|}
\hline Mutation type & Internal mutation & $f^{*}$ & Ranking (tied) \\
\hline Synonymous & 6 & 3 & 7.5 \\
\hline Synonymous & 8 & 3 & 7.5 \\
\hline Synonymous & 35 & 3 & 7.5 \\
\hline Synonymous & 39 & 3 & 7.5 \\
\hline Synonymous & 46 & 3 & 7.5 \\
\hline Synonymous & 47 & 3 & 7.5 \\
\hline Synonymous & 49 & 3 & 7.5 \\
\hline Synonymous & 55 & 3 & 7.5 \\
\hline Synonymous & 61 & 3 & 7.5 \\
\hline Synonymous & 62 & 3 & 7.5 \\
\hline Synonymous & 63 & 3 & 7.5 \\
\hline Synonymous & 4 & 3 & 7.5 \\
\hline Synonymous & 5 & 3 & 7.5 \\
\hline Synonymous & 48 & 3 & 7.5 \\
\hline Synonymous & 2 & 4 & 20.5 \\
\hline Synonymous & 14 & 4 & 20.5 \\
\hline Synonymous & 18 & 4 & 20.5 \\
\hline Synonymous & 29 & 4 & 20.5 \\
\hline Synonymous & 36 & 4 & 20.5 \\
\hline Synonymous & 37 & 4 & 20.5 \\
\hline Synonymous & 43 & 4 & 20.5 \\
\hline Synonymous & 44 & 4 & 20.5 \\
\hline Synonymous & 45 & 4 & 20.5 \\
\hline Synonymous & 60 & 4 & 20.5 \\
\hline Synonymous & 64 & 4 & 20.5 \\
\hline Nonsynonymous & 19 & 4 & 20.5 \\
\hline Synonymous & 17 & 5 & 28 \\
\hline Synonymous & 42 & 5 & 28 \\
\hline Synonymous & 54 & 5 & 28 \\
\hline Synonymous & 7 & 6 & 31 \\
\hline Synonymous & 41 & 6 & 31 \\
\hline Nonsynonymous & 12 & 6 & 31 \\
\hline Synonymous & 40 & 7 & 33 \\
\hline Synonymous & 52 & 10 & 34 \\
\hline Synonymous & 11 & 11 & 36 \\
\hline Nonsynonymous & 9 & 11 & 36 \\
\hline Nonsynonymous & 10 & 11 & 36 \\
\hline Synonymous & 1 & 12 & 38 \\
\hline Synonymous & 34 & 53 & 39 \\
\hline Nonsynonymous & 31 & 55 & 40 \\
\hline Nonsynonymous & 26 & 59 & 42 \\
\hline Nonsynonymous & 27 & 59 & 42 \\
\hline Nonsynonymous & 28 & 59 & 42 \\
\hline Nonsynonymous & 25 & 60 & 44 \\
\hline
\end{tabular}

$f^{*}$ - Number of haplotypes defined by the mutation.

region, which may be postulated to help connecting the BTB to the zinc fingers present at the end of each of the alternative spliced isoforms. The interactions among these isoforms and the involvement of FRU proteins in features directly and indirectly subject to sexual selection offer opportunities for positive selection to occur over some segments of this gene. These several distinct aspects of sexual differentiation could be affected by the connecting region differently than the MOL development, hence the rescue of the latter does not mean that other subtler aspects of the behavior effected by fru such as male courtship song [39], response to sex-pheromones [40] and female post-copulatory behavior [41], would respond similarly. This pattern is akin to what has been described for some central genes in gene networks which are co-opted and assume new functions in different developmental contexts [42]. Such patterns have been observed in several developmental genes, such as some HOX genes, which affect basic pattern formation as well as wing and other appendages formation in arthropods $[43,44]$. It should be mentioned, though, that caution should be taken when considering sexual selection as a sole explanation for the positive selection here found, because fru also codes for non-sex-specific transcripts [12], so it is possible that the signal of adaptive selection may be the result of selection over phenotypes not related to sexual behavior.

\section{Selective pattern in low divergence lineages of Anastrepha}

Both $\mathrm{dN} / \mathrm{dS}$ and MM01 analyses require that the differences among sequences represent fixed substitutions among very well defined lineages $[29,45,46]$. When dealing with data from recently diverged lineages, few fixed substitution are found among sequences, and consequently, the power of the tests to discriminate between positive and purifying selection is reduced [47]. Additionally, recently diverged lineages, such as the species A. fraterculus, A. sororcula and A. obliqua here considered, may still segregate ancestral polymorphisms. For this reason, standard interpretation of $\mathrm{dN} / \mathrm{dS}$ and MM01 statistics could lead to equivocal conclusions and other approaches are required.

Our data cannot be subject to the McDonnald-Kreitman [36] test since there is no fixed interspecific variation for any of the species considered. We may, however, use the same rationale of contrasting recent and old synonymous and nonsynonymous mutations in the framework of the haplotype network. The McDonnald-Kreitman test considers two categories of contrasts, polymorphic and fixed, or recent and old, but there is more information available from the network, particularly the relative frequency of each mutation, which may be an indication of the relative age of a mutation [48]. In a neutrally evolving region, older mutations would tend to be in higher frequencies than new mutations [49], that is why we performed a contrast between synonymous and non-synonymous mutations using a 
non-parametric Mann-Whitney test which investigated the pattern of differential survival between synonymous and nonsynonymous in evolutionary time (Table 6). This Mann-Whitney test rejects the null hypothesis that synonymous and nonsynonymous mutations come from the same distribution, and indicates that nonsynonymous mutations survived longer than synonymous mutations $(p<0.02)$. The excess of low-frequency variants could be explained by many other factor besides positive selection, such as population demographic change and background selection, however, only positive selection and very specific demographic scenarios are able to explain the excess of high frequency mutations [32]. Then the excess of nonsynonymous mutations found in the fru $\mathrm{C} 3$ exon reveals the action of positive selection driving the increase in frequency of such mutations in the $\mathrm{C} 3$ exon. Because this test is dependent on the topology of the haplotype network, which has been shown to vary due to stochastic processes [50], we are currently evaluating the power of this test in different evolutionary scenarios using forward and reversetime simulations, which will be the dealt with elsewhere.

The excess of high frequency mutations detected in the Mann-Whitney test was also detected by the significantly negative Fay and Wu's $H$ which measures the frequency of high derived mutations (Table 5). The Tajima's $D$ and the Fu and Li's $D$ statistics were also significantly negative and indicate an excess of low frequency variants. The joint analysis of different neutrality tests allows for a better evaluation of the influence of selection over this region, since each one is sensitive to a particular aspect of the site frequency spectrum [51]. One evident signal of hitchhiking effect by positive selection is the excess of low and high frequency variants coexisting in the a population after many generations from the selective sweep [32], while the expected pattern for purifying selection would be only the excess of low frequency variants. Therefore, the joint analysis of these neutrality tests confirms that fru $\mathrm{C} 3$ exon from Anastrepha shows signals of positive selection, if not in the region itself, in a closely linked region.

\section{Selective sweep in fru connecting region}

The diversity indexes of the $\mathrm{C} 3$ exon are significantly lower than those of the I3 intron (all z-values $<-5, p<$ 0.001) (Table 4), which would suggest that the intron has been evolving in a less constrained way. This is not surprising since it is expected that non-coding regions, such as introns, would evolve neutrally, though some introns have been described to evolve more conservatively than adjacent coding regions [52]. Interestingly, when we partition the diversity estimates by species we observe a reduction in the diversity levels for the intron in A. obli$q u a$, but not in the adjacent exon. In $A$. obliqua, $\pi$ and $\theta$ values for the intron are three times lower than those estimated for $A$. fraterculus and $A$. sororcula (z-values < $-4, p<0.001$ ) (Table 4). Even the haplotype diversity was twice smaller than the values for the other two species (z-values $<-4, p<0.001)$. If we consider that the intron has evolved neutrally, we would expect similar diversity levels for the three species. Departures from these expectations would suggest that populations have experienced distinct demographic scenarios or different selection events have acted upon the intron or contiguous regions. Because the reduction in intron diversity in A. obliqua was not observed in the contiguous connecting region, it is not likely that it was caused by a recent demographic event, otherwise it should have affected equally the genetic variation in the intron and the coding region $[53,54]$. On the other hand, a selective sweep would lead to a reduction in local genetic variation with increase in frequency of the few polymorphisms associated with the sweep, and depending on its intensity could lead to complete fixation in the region [54]. When only drift and mutation are contributing to the increase of the diversity after such reduction, it takes on average $4 N$ generations for the diversity to reach Fisher-Wright equilibrium levels. If there is purifying selection it would take longer for the equilibrium to be reached, whereas when there is positive selection the favored alleles, or others linked to them, will rapidly recover their high allele frequencies. Therefore, the existence of a previous selective sweep should have longer lasting effects on the genetic variation of neutral regions than on regions under positive selection. The similar genetic variability in the coding region of the three species, coupled with a reduction in the variation in A. obliqua intron, suggests a selective sweep in A. obliqua, from which the intron variation is still recovering, while the variation in the coding region, subjected to positive selection, has already recovered, or was never completely lost. This scenario is more likely if more than one site has been subject to positive selection at the same time [55], as it seems to be the case here. The hypothesis of a recent selective sweep is also corroborated by a starlike haplotype network with an excess of rare haplotypes for the intron, and lower Fay and Wu's $H$ estimates for the coding region than for the intron (Figure 6).

\section{fru as species-specific marker}

The lineage sorting of ancestral polymorphisms makes recently diverged species share alleles throughout their genome causing a conflict between gene tree and species tree for several genes or DNA segments [56]. When only neutral markers are considered it is expected that most of the loci attain reciprocal monophyly only after $9 N_{e}$ generations from the speciation event $[57,58]$, which would take a long time if the species have large effective sizes. Considering that Anastrepha species from 
the fraterculus group have diverged recently $[23,59]$ and should have large effective population sizes, we expect that species in this group will still show high degree of shared ancestral polymorphisms throughout their genome, which has been suggested by previous studies using both mitochondrial and nuclear genes $[23,25,60]$. Even though we did not observe strict reciprocal monophyly when using data from fru, most specimens of $A$. obliqua are separated from the other species by a branch with several mutations, mostly amino acid replacements. In fact, only five haplotypes of this branch belong to specimens that were diagnosed as $A$. fraterculus and four as A. sororcula (Figure 5). When studying genes directly involved in the species reproductive isolation, the ancestral polymorphisms associated with regions under selection would be wiped away at a faster rate, and consequently, one or both diverging groups would be fixed for species-specific variation at that gene before other genome regions [61]. Multilocus studies of closely related species have reported extensive ancestral polymorphisms sharing, but exclusive variation in some genes related to reproductive traits such as pheromone production [62], seminal proteins $[7,63]$ or spermatogenic function [61]. It is possible that the fast evolutionary rate in fru may explain, per se, its more accurate phylogenetic resolution in Anastrepha species, but it may also be due to the fact that this gene is adaptively diverging, and has a role in determining courtship behavior, which could somehow affect reproductive isolation.

\section{Conclusions}

Contrary to Gailey et al. [6], who had considered the high diversification of fru connecting region solely as a consequence of relaxed selective constraint, here we conclude that part of such diversification is due to positive selection. These conclusions are based not only on the comparison of distantly related taxa that show longterm divergence time, but also on recently diverged lineages and suggest that the episodes of adaptive evolution in $f r u$ may be related to sexual selection and/or conflict related to its involvement in male courtship behavior. Because the findings of an association between fru variation and the isolation of A. obliqua may only be because they had occurred historically concurrently, we need a more detailed study that considers the entire fru gene, as well as its interaction with other genes from the sexual differentiation cascade in more species to better investigate the role of the fru gene in the differentiation of this group and others.

\section{Methods}

Fruits from different plant species that are known to be infested by Anastrepha were collected from 33 localities in Brazil (Table 7) and set in vermiculite for 14 days when pupae were separated. After emergence and maturation, flies that were identified as belonging to the A. fraterculus group, mostly $A$. fraterculus, A. obliqua and $A$. sororcula, were separated and immediately processed or preserved in 95\% ethanol until DNA extraction.

\section{DNA extraction and sequencing}

DNA was extracted following the modified protocol of [64], in which the exoskeletons were maintained intact for future morphological analyses. We amplified a region from the end of the BTB domain to next the end of first exon of the connecting region of fru (C3 exon) (Figure 1B), using degenerate primers created from homologous sequences of closely related species: (5'AGTTCGCTGCCGATGTTYCTCAA-3' and 5'GACAGRCACTAYCCGCAGGACTCTCAG-3'). This region was amplified by PCR from genomic DNA in a thermocycler PTC-200 (BioRad) using an admixture of Taq polymerase and $P f u$ polymerase to reduce incorporating errors [65]. PCR products were purified by PEG 8000 precipitation [66] and cloned with InsTAclone kit (Fermentas). At least two recombinant colonies were sequenced with forward and reverse M13 primers using the DYEnamic ${ }^{\text {Ts }} E T$ dye terminator kit (GE Healthcare) and resolved either in a MegaBace 1000 (GE Healthcare) or in an ABI 3730 (Applied). DNA sequencing was mostly carried out at MACROGEN INC, Korea. Quality of base-calling was visually inspected in Chromas version 2.31 http://www.technelysium.com.au. The GenBank accession numbers for the 97 sequences from $A$. fraterculus, A. sororcula and A. obliqua are [HQ003715 - HQ003811. We used the translation of these Anastrepha exon sequences to proteins to align this region to more distantly related taxa. The protein alignments were used as reference to correct alignments of nucleotide sequences, which were used in the phylogenetic tree estimation. Sequences were aligned and visually inspected using Clustal W in BioEdit Sequence Alignment Editor software [67]. When sequenced clones from an individual differed by less than 3 mutations, additional recombinant colonies (up to five total) were sequenced to confirm results.

\section{fruitless evolution}

We used a hierarchical strategy to test for selection on fru sequences. First we evaluated patterns of long-term evolutionary response to selection (i. e., a deeper phylogenetic level), by contrasting a sample of sequences from Anastrepha species against sequences from other Muscomorpha. We also tested for patterns of selection which may be detected at the population level, contrasting fru sequences from the connecting region and preceding intron gathered from Anastrepha collected from several localities in Brazil. 
Table 7 Sampling locations with geographic, haplotype and species information

\begin{tabular}{|c|c|c|c|c|}
\hline Code & Collection locality & $\begin{array}{l}\text { Latitude } \\
\text { (S) }\end{array}$ & $\begin{array}{l}\text { Longitude } \\
\text { (W) }\end{array}$ & Haplotype \\
\hline 01 & São Carlos - SP & $22^{\circ} 01^{\prime} 03^{\prime \prime}$ & $47^{\circ} 53^{\prime} 27^{\prime \prime}$ & $1-f .1,2-f .1$ \\
\hline 02 & Vitória - ES & $20^{\circ} 19^{\prime} 10^{\prime \prime}$ & $40^{\circ} 20^{\prime} 16^{\prime \prime}$ & $38-0.2,39-0.2,72-0.2,73-0.2$ \\
\hline 03 & Feira do Santana -BA & $12^{\circ} 16^{\prime} 00^{\prime \prime}$ & $38^{\circ} 58^{\prime} 00^{\prime \prime}$ & $69-0.3,70-0.3$ \\
\hline 04 & Gurupi - TO & $11^{\circ} 43^{\prime} 45^{\prime \prime}$ & $49^{\circ} 04^{\prime} 07^{\prime \prime}$ & 57-0.4, 58-0.4 \\
\hline 05 & São Sebastião - SP & $23^{\circ} 45^{\prime} 36^{\prime \prime}$ & $45^{\circ} 24^{\prime} 35^{\prime \prime}$ & 8-f.5, 9-f.5, 82-s.5, 83-s.5 \\
\hline 06 & Bertioga - SP & $23^{\circ} 51^{\prime} 16^{\prime \prime}$ & $46^{\circ} 08^{\prime} 19^{\prime \prime}$ & $20-f .6,21-f .6$ \\
\hline 07 & Conceição do Almeida - BA & $12^{\circ} 46^{\prime} 46^{\prime \prime}$ & $39^{\circ} 10^{\prime} 12^{\prime \prime}$ & 28-f.7, 29-f.7, 30-f.7, 31-f.7 \\
\hline 08 & Araguaína - TO & $07^{\circ} 11^{\prime} 28^{\prime \prime}$ & $48^{\circ} 12^{\prime} 26^{\prime \prime}$ & $40-0.8,41-0.8,42-0.8,43-0.8,44-0.8,45-0.8,46-0.8,47-0.8$ \\
\hline 09 & Santo Amaro - BA & $12^{\circ} 32^{\prime} 48^{\prime \prime}$ & $38^{\circ} 42^{\prime} 43^{\prime \prime}$ & 1-f.9, 27-f.9, 65-o.9, 66-o.9, 67-0.9, 68-0.9 \\
\hline 10 & Goiânia - GO & $16^{\circ} 40^{\prime} 43^{\prime \prime}$ & $49^{\circ} 15^{\prime} 14^{\prime \prime}$ & $50-0.10,51-0.10$ \\
\hline 11 & Bonito - PE & $08^{\circ} 28^{\prime} 13^{\prime \prime}$ & $35^{\circ} 43^{\prime} 43^{\prime \prime}$ & 3-f.11, 4-f.11, 5-f.11, 77-s.11, 78-s.11, 79-s.11 \\
\hline 12 & Redenção - PA & $08^{\circ} 01^{\prime} 43^{\prime \prime}$ & $50^{\circ} 01^{\prime} 53^{\prime \prime}$ & $52-0.12,53-0.12,54-0.12$ \\
\hline 13 & Babaçulândia - TO & $07^{\circ} 12^{\prime} 17^{\prime \prime}$ & $47^{\circ} 45^{\prime} 25^{\prime \prime}$ & $38-0.13,3-0.13$ \\
\hline 14 & Pirenópolis - GO & $15^{\circ} 51^{\prime} 09^{\prime \prime}$ & $48^{\circ} 57^{\prime} 33^{\prime \prime}$ & $55-0.14,56-0.14$ \\
\hline 15 & Três Lagoas - MS & $20^{\circ} 45^{\prime} 04^{\prime \prime}$ & $51^{\circ} 40^{\prime} 42^{\prime \prime}$ & $61-0.15,62-0.15$ \\
\hline 16 & Belém -PA & $01^{\circ} 27^{\prime} 21^{\prime \prime}$ & $48^{\circ} 30^{\prime} 16^{\prime \prime}$ & 63-0.16, 64-0.16 \\
\hline 18 & Belo Horizonte - MG & $19^{\circ} 55^{\prime} 15^{\prime \prime}$ & $43^{\circ} 56^{\prime} 16^{\prime \prime}$ & $71-0.18$ \\
\hline 19 & Bela Vista de Goiás - GO & $16^{\circ} 58^{\prime} 22^{\prime \prime}$ & $48^{\circ} 57^{\prime} 12^{\prime \prime}$ & 48-0.19, 49-0.19 \\
\hline 20 & Linhares - ES & $19^{\circ} 23^{\prime} 28^{\prime \prime}$ & $40^{\circ} 04^{\prime} 20^{\prime \prime}$ & 74-o.20, 75-o.20, 94-s.20, 95-s.20 \\
\hline 21 & Piracicaba - SP & $22^{\circ} 43^{\prime} 31^{\prime \prime}$ & $47^{\circ} 38^{\prime} 57^{\prime \prime}$ & $84-s .21,85-s .21,86-s .21,87-s .21$ \\
\hline 22 & Nova Souré - BA & $11^{\circ} 14^{\prime} 00^{\prime \prime}$ & $38^{\circ} 29^{\prime} 00^{\prime \prime}$ & $92-s .22,93-s .22$ \\
\hline 23 & Bauru - SP & $22^{\circ} 18^{\prime} 53^{\prime \prime}$ & $49^{\circ} 03^{\prime} 38^{\prime \prime}$ & 24-f.23, 25-f.23, 88-s.23, 89-s.23, 90-s.23, $91-$ s.23 \\
\hline 24 & Porto Seguro - BA & $16^{\circ} 26^{\prime} 59^{\prime \prime}$ & $39^{\circ} 03^{\prime} 53^{\prime \prime}$ & $80-5.24,81-5.24$ \\
\hline 25 & Boracéia - SP & $22^{\circ} 11^{\prime} 35^{\prime \prime}$ & $48^{\circ} 46^{\prime} 44^{\prime \prime}$ & $10-f .25,11-f .25$ \\
\hline 26 & Bariri - SP & $22^{\circ} 04^{\prime} 28^{\prime \prime}$ & $48^{\circ} 44^{\prime} 25^{\prime \prime}$ & $12-f .26,13-f .26$ \\
\hline 27 & Itabira - MG & $19^{\circ} 37^{\prime} 09^{\prime \prime}$ & $43^{\circ} 13^{\prime} 37^{\prime \prime}$ & $6-f .27,7-f .27$ \\
\hline 28 & Moji das Cruzes - SP & $23^{\circ} 31^{\prime} 22^{\prime \prime}$ & $46^{\circ} 11^{\prime} 18^{\prime \prime}$ & $22-f .28,23-f .28$ \\
\hline 29 & Vacaria - RS & $28^{\circ} 30^{\prime} 44^{\prime \prime}$ & $50^{\circ} 56^{\prime} 02^{\prime \prime}$ & 32-f.29, 33-f.29, 34-f.29, 35-f.29 \\
\hline 30 & Vargem Alta - ES & $20^{\circ} 40^{\prime} 17^{\prime \prime}$ & $41^{\circ} 00^{\prime} 25^{\prime \prime}$ & 16-f.30, 17-f.30, 18-f.30, 19-f.30 \\
\hline 31 & Natal - RN & $05^{\circ} 47^{\prime} 42^{\prime \prime}$ & $35^{\circ} 12^{\prime} 34^{\prime \prime}$ & $14-f .31,15-f .31$ \\
\hline 32 & Caçador - SC & $26^{\circ} 46^{\prime} 31^{\prime \prime}$ & $51^{\circ} 00^{\prime} 54^{\prime \prime}$ & 36-f.32, 37-f.32 \\
\hline 33 & Santa Isabel - SP & $23^{\circ} 18^{\prime} 0^{\prime \prime}$ & $46^{\circ} 13^{\prime} 0^{\prime \prime}$ & $76-0.33$ \\
\hline
\end{tabular}

The numbers in haplotypes represent their identification and the letters represent the species at which they were found: o - A. obliqua; $f-A$. fraterculus; $s-A$. sororcula. Numbers after the letter stand for collection locality code.

\section{Phylogenetic tree reconstruction}

To reconstruct the phylogenetic tree an optimal nucleotide substitution model was determined by Akaike information criterion (AIC) using MODELTEST ver. 3.7 [68] implemented in the $H y P H y$ package ver 0.95 beta [69]. A phylogenetic tree using sequences from fru C3 exon was estimated by maximum likelihood using the software PhyML ver. 3.0 [70] under the TIM+G nucleotide substitution model estimated previously. For the phylogenetic tree reconstruction we used one sequence from each of the Anastrepha species studied in this work ( $A$. fraterculus [GenBank accession number: HQ003715], $A$. sororcula [GenBank accession number: 1376936] and $A$. obliqua [GenBank accession number: HQ003765]) to represent the Tephritidae lineage, and 10 different sequences from Drosophilidae available in GenBank: $D$. simulans - [AF297054.1]; D. sechellia - [AF297055.1]; D. melanogaster - [D84437.1]; D. erecta - [AF298222.1]; D. yakuba - [AF297056.1]; D. heteroneura [AF051668.1]; D. silvestris - [AF051665.1]; D. grimshawi - [AF105124.1]; D. virilis - [AY028967.1] and D. pseudoobscura - [AF297059.1].

\section{Long-term response to selection in fruitless}

In order to investigate selective pressures that modeled the evolution of $f r u$, we performed a relaxed branch-site test and a strict branch-site test $[71,72]$ using the software CODEML, implemented in PAML ver. 4 [73]. The nonsynonymous/synonymous substitutions rate ratios $(\mathrm{dN} / \mathrm{dS}=\omega)$ were measured to infer the selective pressure at the protein level. A $\omega>1$ at a specific site would indicate positive selection, because nonsynonymous 
substitutions would have higher fixation probabilities than synonymous mutations due to selective advantages. On the other hand, a $\omega<1$ would indicate purifying selection, caused by selective constraints at the codon position. The branch-site tests consider the phylogenetic tree to test different selective scenarios. The phylogenetic tree was separated in foreground branches, at which positive selection is tested, and background branches, represented by the other lineages. We established the Anastrepha branch as foreground and the other Drosophila species as background. Positive selection was inferred by a contrast of hypotheses using a maximum likelihood approach. Both relaxed branch-site test and strict branch-site test use the MA model as alternative model, in which the codons in the foreground were allowed to have $\omega>1$, and the codons in background were constrained to $\omega \leq 1$. The relaxed branchsite test null model (M1a) assumes the same evolutionary rates for all sites and branches, with all sites varying $\omega$ values from 0 and 1 . On the other hand, the strict branch-site test fixes the $\omega>1$ category to 1 in the null model (restricted MA), that is, all sites with $\omega>1$ are forced to evolve neutrally $(\omega=1)$. Positive selection is inferred when a log likelihood ratio test (LRT) of these values results in a significant value. To assess significance of the LRT we used a chi-squared null distribution composed of a mixture of point mass 0 and $\chi_{1}^{2}$. Under such null distribution the critical values at 0.05 and 0.01 levels were 2.71 and 5.41, respectively [71]. Bayes Empirical Bayes [28] method was used in conjunction with the branch-site test to estimate which sites were under the influence of positive selection. We used the MA model parameters to estimate the Bayes Empirical Bayes posterior probabilities. Because some models are prone to show a problem of lack of convergence in a likelihood framework, we ran the analyses twice with different initial $\omega$ values.

Positive selection was also investigated through the MM01 method of McClellan et al. [46] which evaluates whether nonsynonymous substitutions favored or not structural or functional changes in the protein. The analyses were carried out in TreeSAAP version 3.2 $[46,74,75]$ and considered the changes in many physicochemical properties brought forth by each nonsynonymous substitution. A global deviation from neutrality is verified by a goodness-of-fit test between a neutral expected distribution and the observed distribution of the selected physicochemical properties [46]. Furthermore, TreeSAAP also separates the magnitude of nonsynonymous changes in a range going from conservative to very radical substitutions, according to the change in specific physicochemical properties. The lowest classes ( 1 to 3 ) represent the more conservative changes and the highest classes (6 to 8) represent the more radical changes [46]. McClellan et al. [46] conservatively defined stabilizing selection as a selection that tends to maintain the original biochemical attributes of the protein, despite the fact of the inference of positive selection, and destabilizing selection as a selection that favors structural and functional shifts in a region of a protein. In this way, positive-destabilizing selection represents a signature of molecular adaptation.

We considered 8 categories of magnitude change for the analysis and followed the categorization given in McClellan et al. [46]. Only amino acid properties identified by significant positive $\mathrm{z}$-score in the magnitude categories 6,7 or 8 were considered to be affected by positive-destabilizing selection. To verify which specific regions were affected by positive-destabilizing selection, we performed a sliding window analysis using the amino acid properties which were significant for this type of change. Sliding windows of 20 amino acid length with a sliding step of one codon were selected for showing the best signal-to-noise ratio [45].

\section{Genetic diversity and population evolutionary analyses}

General diversity indexes, such as haplotype $(H d)$ and nucleotide $(\pi)$ diversity [76], number of polymorphic sites, synonymous nucleotide diversity $\left(\pi_{\mathrm{s}}\right)$ and nonsynonymous nucleotide diversity $\left(\pi_{\mathrm{a}}\right)$ were calculated using DnaSP version 5 [77]. The significance of comparison among diversity indexes were accessed by a two sample z-test for comparison between means [78]. fru C3 exon and I3 intron haplotype networks were inferred by TCS $v 1.21$ software [79] using statistical parsimony with a $95 \%$ connection significance [80], and was manually converted to Newick tree format for some of the neutrality tests. Because recombination interferes with phylogenetic inferences, we performed three different methods to detect recombination events: GENECONV [81] and $R D P$ both implemented in $R D P$ version $3 \mathrm{~b} 14$ [82]. Tajima's $D$ [30], Fu and Li's $D$ and $F$ [31] and Fay and Wu's $H$ [32] neutrality tests were performed in DnaSP version 5 [77] using a sequence from Drosophila melanogaster (GenBank access number: D84437.1) as an outgroup for the fru C3 exon analysis and from Ceratitis capitata (GenBank access number: AF124047.1) for intron analyses. We used different outgroup sequences because the $C$. capitata sequence available on GenBank included only a small portion of the $\mathrm{C} 3$ exon, and the D. melanogaster intron showed higher divergence in relation to the sequences obtained in this work, and, as a consequence, its correct alignment was impaired.

One test commonly used to analyze populational data is the McDonnald-Kreitman's test [36], which contrasts fixation and polymorphism levels of synonymous and non-synonymous substitutions for two species in a 
contingency table [36]. Our data cannot be subjected to McDonnald-Kreitman test since there is no fixed interspecific variation for any of the species considered. We may, however, use a modification of the test proposed by Templeton [37] which implements the contrast of synonymous and nonsynonymous substitutions in tip and interior haplotypes (populational equivalents to the young and old haplotypes contrast of McDonnald-Kreitman test, respectively). Under neutrality synonymous and nonsynonymous substitutions are expected to occur in a same rate both in tip and interior haplotypes, whereas at purifying or positive selection such rate are biased toward synonymous or nonsynonymous substitutions, respectively. We propose here an alternative test of selection which evaluates whether synonymous substitutions have a greater probability of surviving in the population when compared to nonsynonymous substitutions. In a neutrally evolving region, we expect that the probabilities of survival of synonymous and nonsynonymous substitutions through time should come from the same probability distribution. On the other hand, if the region is under purifying selection, we expect that nonsynonymous substitutions have a higher chance of being eliminated [83], whereas if the region is under positive selection, we would find several advantageous nonsynonymous substitutions with higher probability of surviving and spreading in the population [54]. In order to detect this pattern in selection signals, we evaluate the number of haplotypes that derived from each mutation directly from a haplotype network. Because recent mutations, such as those present as singletons or doubletons in the tips of the haplotype network, may not yet have passed through the evolutionary test of survival and reproduction over time [37] and are more affected by drift and chance, we only consider mutations present in at least three haplotypes. To contrast the differential survival probabilities of synonymous and nonsynonymous substitutions in the population, we ranked internal synonymous and nonsynonymous mutations in the haplotype network according to the number of descendent haplotypes derived from them and calculate the difference in synonymous and nonsynonymous ranks summation (R1 and R2) in an improved normal approximation to the Mann-Whitney test [84]. If synonymous and nonsynonymous mutations come from the same distribution, we do not expect to see a significant difference in their ranks, i.e., in neutrality, we expect that synonymous and nonsynonymous mutations should have similar probabilities of survival in a population, and therefore, similar ranks. On the other hand, if nonsynonymous mutations have been selected against, we expect that synonymous mutations would be on average older, and therefore have higher ranks than nonsynonymous mutations, and the opposite would be true if the region is under positive selection. Because it has been shown that tests of selection that rely on the comparison of rates of nonsynonymous to synonymous substitutions have limited power when contrasting sequences with little differentiation $[29,47]$, this test is adequate to look for patterns of selection at the population level by using information derived from the phylogenetic relationships amongst the haplotypes.

\section{Acknowledgements}

We would like to thank Dr. Keiko Uramoto for help in identifying the specimens here studied, Dr. Alan R. Templeton for help in discussing the Mann-Whitney analysis and two anonymous referees for contributions to a previous version of this manuscript. Iderval S Sobrinho Jr. was supported by a fellowship from CAPES and is currently a post-doc under another CAPES Fellowship (PNPD/CAPES). This project was funded by FAPESP grants 2007/ 00500-2 and 2009/03189-1 to Reinaldo A. de Brito.

\section{Authors' contributions}

ISSJ and RAB designed the experiments. ISSJ collected the data. ISSJ and RAB analyzed the data and wrote the manuscript. All authors read and approved the final manuscript.

Received: 27 April 2010 Accepted: 24 September 2010

Published: 24 September 2010

\section{References}

1. Swanson WJ, Vacquier VD: The rapid evolution of reproductive proteins. Nature Reviews Genetics 2002, 3:137-144.

2. Gerrard DT, Meyer A: Positive selection and gene conversion in SPP120, a fertilization-related gene, during the east african cichlid fish radiation. Molecular Biology and Evolution 2007, 24:2286-2297.

3. Swanson WJ, Wong A, Wolfner MF, Aquadro CF: Evolutionary expressed sequence tag analysis of Drosophila female reproductive tracts identifies genes subjected to positive selection. Genetics 2004, 168:1457-1465.

4. Clark NL, Swanson WJ: Pervasive adaptive evolution in primate seminal proteins. PLoS Genet 2005, 1:e35.

5. Kulathinal RJ, Skwarek L, Morton RA, Singh RS: Rapid evolution of the sexdetermining gene, transformer: Structural diversity and rate heterogeneity among sibling species of Drosophila. Molecular Biology and Evolution 2003, 20:441-452.

6. Gailey DA, Billeter JC, Liu JH, Bauzon F, Allendorfer JB, Goodwin SF: Functional conservation of the fruitless male sex-determination gene across 250 Myr of insect evolution. Molecular Biology and Evolution 2006, 23:633-643.

7. Andrés JA, Maroja LS, Harrison RG: Searching for candidate speciation genes using a proteomic approach: seminal proteins in field crickets. Proceedings of the Royal Society B: Biological Sciences 2008, 275:1975-1983.

8. Orr HA, Masly JP, Presgraves DC: Speciation genes. Current Opinion in Genetics \& Development 2004, 14:675-679.

9. Cho $S$, Huang $Z Y$, Zhang J: Sex-specific splicing of the honeybee doublesex gene reveals 300 Million years of evolution at the bottom of the insect sex-determination pathway. Genetics 2007, 177:1733-1741.

10. Pane A, De Simone A, Saccone G, Polito C: Evolutionary conservation of Ceratitis capitata transformer gene function. Genetics 2005, 171:615-624.

11. Schütt C, Nöthiger R: Structure, function and evolution of sexdetermining systems in Dipteran insects. Development 2000, 127:667-677.

12. Demir $E$, Dickson BJ: fruitless splicing specifies male courtship behavior in Drosophila. Cell 2005, 121:785-794.

13. Kyriacou CP: Sex in fruitflies is fruitless. Nature 2005, 436:334-335.

14. Kimura Ki, Hachiya T, Koganezawa M, Tazawa T, Yamamoto D: Fruitless and doublesex coordinate to generate male-specific neurons that can initiate courtship. Neuron 2008, 59:759-769.

15. Rideout EJ, Dornan AJ, Neville MC, Eadie S, Goodwin SF: Control of sexual differentiation and behavior by the doublesex gene in Drosophila melanogaster. Nature Neuroscience 2010, 13:458-466. 
16. Bertossa RC, van de Zande L, Beukeboom LW: The fruitless gene in Nasonia displays complex sex-specific splicing and contains new zinc finger domains. Molecular Biology and Evolution 2009, 26:1557-1569.

17. Usui-Aoki K, Ito H, Ui-Tei K, Takahashi K, Lukacsovich T, Awano W, Nakata H, Piao ZF, Nilsson EE, Tomida Jy, et al: Formation of the male-specific muscle in female Drosophila by ectopic fruitless expression. Nat Cell Biol 2000, 2:500-506.

18. Song HJ, Billeter JC, Reynaud E, Carlo T, Spana EP, Perrimon N, Goodwin SF, Baker BS, Taylor BJ: The fruitless gene is required for the proper formation of axonal tracts in the embryonic central nervous system of Drosophila. Genetics 2002, 162:1703-1724

19. Anand A, Villella A, Ryner LC, Carlo T, Goodwin SF, Song HJ, Gailey DA, Morales A, Hall JC, Baker BS, et al: Molecular genetic dissection of the sexspecific and vital functions of the Drosophila melanogaster sex determination gene fruitless. Genetics 2001, 158:1569-1595.

20. Malavasi A: Biogeografia. In Moscas-das-frutas de importância econômica no Brasil - Conhecimento básico e aplicado. Edited by: Malavasi A, Zucchi RA. Ribeirão Preto, SP: Holos Editora; 2000:

21. Araujo EL, Zucchi RA: Medidas do acúleo na caracterização de cinco espécies de Anastrepha do grupo fraterculus (Diptera: Tephritidae). Neotropical Entomology 2006, 35:329-337.

22. Selivon D, Perondini ALP, Morgante JS: A genetic-morphological characterization of two cryptic species of the Anastrepha fraterculus complex (Diptera: Tephritidae). Annals of the Entomological Society of America 2005, 98:367-381.

23. Smith-Caldas MRB, Mcpheron BA, Silva JG, Zucchi RA: Phylogenetic relationships among species of the fraterculus group (Anastrepha: Diptera: Tephritidae) inferred from DNA sequences of mitochondrial cytochrome oxidase I. Neotropical Entomology 2001, 30:565-573.

24. Ruiz MF, Stefani RN, Mascarenhas RO, Perondini ALP, Selivon D, Sanchez L: The gene doublesex of the fruit fly Anastrepha obliqua (Diptera, Tephritidae). Genetics 2005, 171:849-854.

25. Ruiz MF, Milano A, Salvemini M, Eirín-López JM, Perondini ALP, Selivon D, Polito C, Saccone G, Sánchez L: The gene transformer of Anastrepha fruit flies (Diptera, Tephritidae) and its evolution in insects. PLOS ONE 2007, 2 e1239.

26. Yang Z, Swanson WJ: Codon-substitution models to detect adaptive evolution that account for heterogeneous selective pressures among site classes. Molecular Biology and Evolution 2002, 19:49-57.

27. Kosakovsky Pond SL, Poon AFY, Leigh Brown AJ, Frost SDW: A Maximum likelihood method for detecting directional evolution in protein sequences and its application to influenza A virus. Molecular Biology and Evolution 2008, 25:1809-1824.

28. Yang Z, Wong WSW, Nielsen R: Bayes empirical Bayes inference of amino acid sites under positive selection. Molecular Biology and Evolution 2005, 22:1107-1118

29. Kryazhimskiy S, Plotkin JB: The population genetics of dN/dS. PLoS Genet 2008, 4:1-10

30. Tajima F: The effect of change in population size on DNA polymorphism. Genetics 1989, 123:597-601.

31. Fu Y-X, Li W-H: Statistical tests of neutrality of mutations. Genetics 1993, 133:693-709.

32. Fay JC, Wu C-I: Hitchhiking under positive darwinian selection. Genetics 2000, 155:1405-1413.

33. Achaz G: Frequency spectrum neutrality tests: One for all and all for one. Genetics 2009, 183:249-258.

34. Fu YX: Statistical Tests of Neutrality of Mutations Against Population Growth, Hitchhiking and Background Selection. Genetics 1997 147:915-925.

35. Depaulis F, Veuille M: Neutrality tests based on the distribution of haplotypes under an infinite-site model. Molecular Biology and Evolution 1998, 15:1788-1790.

36. McDonald JH, Kreitman M: Adaptive protein evolution at the Adh locus in Drosophila. Nature 1991, 351:652-654.

37. Templeton AR: Contingency tests of neutrality using intra/interspecific gene trees: The rejection of neutrality for the evolution of the mitochondrial cytochrome oxidase II gene in the hominoid primates. Genetics 1996, 144:1263-1270.

38. Billeter JC, Villella A, Allendorfer JB, Dornan AJ, Richardson M, Gailey DA, Goodwin SF: Isoform-specific control of male neuronal bifferentiation and behavior in Drosophila by the fruitless gene. Current Biology 2006, 16:1063-1076.

39. Clyne JD, Miesenböck G: Sex-specific control and tuning of the pattern generator for courtship song in Drosophila. Cell 2008, 133:354-363.

40. Kurtovic A, Widmer A, Dickson BJ: A single class of olfactory neurons mediates behavioural responses to a Drosophila sex pheromone. Nature 2007, 446:542-546.

41. Häsemeyer M, Yapici N, Heberlein U, Dickson BJ: Sensory neurons in the Drosophila genital tract regulate female reproductive behavior. Neuron 2009, 61:511-518.

42. Monteiro A, Podlaha O: Wings, Horns, and Butterfly Eyespots: How Do Complex Traits Evolve? PLOS Biol 2009, 7:e1000037.

43. Panganiban G, Nagy L, Carroll SB: The role of the Distal-less gene in the development and evolution of insect limbs. Current Biology 1994, 4:671-675.

44. Monteiro A, Glaser G, Stockslager S, Glansdorp N, Ramos D: Comparative insights into questions of lepidopteran wing pattern homology. $B M C$ Developmental Biology 2006, 6:52.

45. Porter ML, Cronin TW, McClellan DA, Crandall KA: Molecular characterization of crustacean visual pigments and the evolution of pancrustacean opsins. Molecular Biology and Evolution 2007, 24:253-268.

46. McClellan DA, Palfreyman EJ, Smith MJ, Moss JL, Christensen RG, Sailsbery JK: Physicochemical evolution and molecular adaptation of the cetacean and artiodactyl cytochrome b proteins. Molecular Biology and Evolution 2005, 22:437-455.

47. Nickel GC, Tefft DL, Goglin K, Adams MD: An empirical test for branchspecific positive selection. Genetics 2008, 179:2183-2193.

48. Castelloe J, Templeton AR: Root probabilities for intraspecific gene trees under neutral coalescent theory. Molecular Phylogenetics and Evolution 1994, 3:102-113

49. Donnelly P, Tavare S: The ages of alleles and a coalescent. Advances in Applied Probability 1986, 18:1-19.

50. Hudson RR: Gene genealogies and the coalescent process. Oxford Surveys in Evolutionary Biology 1990, 7:1-44.

51. Zeng K, Mano S, Shi S, Wu C-l: Comparisons of site- and haplotypefrequency methods for detecting positive selection. Molecular Biology and Evolution 2007, 24:1562-1574.

52. McAllister BF, McVean GAT: Neutral evolution of the sex-determining gene transformer in Drosophila. Genetics 2000, 154:1711-1720.

53. Templeton AR: Population genetics and microevolutionary theory Hoboken: John Wiley and Sons, Inc. 2006.

54. Fay JC, Wu C-I: Detecting hitchhiking from patterns of DNA polymorphism. In Selective Sweep. Edited by: Nurminsky D. New York and Gerogetown: Eurekah.com and Kluwer Academic/Plenum Publishers; , 1 2005:65-77.

55. Chevin LM, Billiard S, Hospital F: Hitchhiking both ways: Effect of two interfering selective sweeps on linked neutral variation. Genetics 2008, 180:301-316

56. Maddison WP: Gene trees in species trees. Systematic Biology 1997, 46:523-536.

57. Hudson RR, Coyne JA, Huelsenbeck J: Mathematical consequences of the genealogical species concept. Evolution 2002, 56:1557-1565.

58. Tajima F: Evolutionary relationship of DNA sequences in finite populations. Genetics 1983, 105:437-460.

59. Morgante JS, Malavasi A, Bush GL: Biochemical systematics and evolutionary relationships of neotropical Anastrepha. Annals of the Entomological Society of America (USA) 1980, 73:622-630.

60. Ruiz MF, Eirín-López JM, Stefani RN, Perondini ALP, Selivon D, Sánchez L: The gene doublesex of Anastrepha fruit flies (Diptera, Tephritidae) and its evolution in insects. Development Genes and Evolution 2007, 217:675-731.

61. Ting CT, Tsaur SC, Wu Cl: The phylogeny of closely related species as revealed by the genealogy of a speciation gene, Odysseus. Proceedings of the National Academy of Sciences of the United States of America 2000, 97:5313-5316.

62. Dopman EB, Pérez L, Bogdanowicz SM, Harrison RG: Consequences of reproductive barriers for genealogical discordance in the European corn borer. Proceedings of the National Academy of Sciences of the United States of America 2005, 102:14706-14711.

63. Maroja LS, Andrés JA, Harrison RG: Genealogical discordance and patterns of introgression and selection across a cricket hybrid zone. Evolution 2009, 63:2999-3015. 
64. Chomczynski P, Sacchi N: Single-step method of RNA isolation by acid guanidinium thiocyanate-phenol-chloroform extraction. Analytical Biochemistry 1987, 162:156-159.

65. Cline J, Braman JC, Hogrefe HH: PCR fidelity of pfu DNA polymerase and other thermostable DNA polymerases. Nucl Acids Res 1996, 24:3546-3551.

66. Lis JT, Schleif R: Size fractionation of double-stranded DNA by precipitation with polyethylene glycol. Nucl Acids Res 1975, 2:383-390.

67. Hall TA: BioEdit: a user-friendly biological sequence alignment editor and analysis program for Windows 95/98/NT. Nucleic Acids Symposium Series 1999, 41:95-98.

68. Posada D, Crandall KA: MODELTEST: testing the model of DNA substitution. Bioinformatics 1998, 14:817-818.

69. Pond SLK, Frost SDW, Muse SV: HyPhy: hypothesis testing using phylogenies. Bioinformatics 2005, 21:676-679.

70. Guindon S, Gascuel O: A Simple, Fast, and Accurate Algorithm to Estimate Large Phylogenies by Maximum Likelihood. Systematic Biology 2003, 52:696-704.

71. Zhang J, Nielsen R, Yang Z: Evaluation of an improved branch-site likelihood method for detecting positive selection at the molecular level. Molecular Biology and Evolution 2005, 22:2472-2479.

72. Yang Z, Nielsen R: Codon-substitution models for detecting molecular adaptation at individual sites along specific lineages. Molecular Biology and Evolution 2002, 19:908-917.

73. Yang Z: PAML 4: Phylogenetic analysis by maximum likelihood. Molecular Biology and Evolution 2007, 24:1586-1591.

74. Woolley S, Johnson J, Smith MJ, Crandall KA, McClellan DA: TreeSAAP: Selection on amino acid properties using phylogenetic trees. Bioinformatics 2003, 19:671-672.

75. McClellan DA, McCracken KG: Estimating the influence of selection on the variable amino acid sites of the cytochrome $b$ protein functional domains. Molecular Biology and Evolution 2001, 18:917-925.

76. Nei M: Molecular Evolutionary Genetics New York: Columbia Univ. Press 1987

77. Librado P, Rozas J: DnaSP v5: a software for comprehensive analysis of DNA polymorphism data. Bioinformatics 2009, 25:1451-1452.

78. Sheskin DJ: Inferential statistical tests employed with two independent samples (and related measures of association/correlation). Handbook of parametric and nomparametric statistical procedures Boca Raton, Florida USA: Chapman and Hall/CRC, 3 2004, 373-413.

79. Clement M, Posada D, Crandall KA: TCS: a computer program to estimate gene genealogies. Molecular Ecology 2000, 9:1657-1659.

80. Templeton AR, Crandall KA, Sing CF: A cladistic analysis of phenotypic associations with haplotypes inferred from restriction endonuclease mapping and DNA sequence data. III. cladogram estimation. Genetics 1992, 132:619-633

81. Sawyer S: Statistical tests for detecting gene conversion. Molecular Biology and Evolution 1989, 6:526-538.

82. Martin D, Rybicki E: RDP: Detection of recombination amongst aligned sequences. Bioinformatics 2000, 16:562-563.

83. Yang Z: Inference of selection from multiple species alignments. Current Opinion in Genetics \& Development 2002, 12:688-694.

84. Hodges JL Jr, Ramsey PH, Wechsler S: Improved significance probabilities of the Wilcoxon test. Journal of Educational Statistics 1990, 15:249-265.

\section{doi:10.1186/1471-2148-10-293}

Cite this article as: Sobrinho and de Brito: Evidence for positive

selection in the gene fruitless in Anastrepha fruit flies. BMC Evolutionary Biology 2010 10:293.

\section{Submit your next manuscript to BioMed Central and take full advantage of:}

- Convenient online submission

- Thorough peer review

- No space constraints or color figure charges

- Immediate publication on acceptance

- Inclusion in PubMed, CAS, Scopus and Google Scholar

- Research which is freely available for redistribution

Submit your manuscript at www.biomedcentral.com/submit
Biomed Central 